\title{
Implementation of Active Learning Strategies based on Continuous Evaluation and Research Approach to Enhance Engineering Students Performances
}

\author{
E. Fosso-Kankeu
}

\begin{abstract}
In this study 55 engineering students participated in a survey aiming to obtain their viewpoint regarding the quality of the teaching strategy used and the impact on their participation and performance with regard to the module considered. The passing rate of the students for the same module during the two years of implementation of the teaching strategy was used to assess students' performance. It was found that in majority $(80 \%)$ students agreed that the new teaching approach resulted in significant improvement of the understanding of the module and academic achievement. The evaluation of the rate of students passing the module after the first opportunity shows that there was 5\% (from 83 to $88 \%$ passing) improvement after implementation of the new teaching strategy. Further investigation is needed to ensure consistency and determine responses to new academic challenges.
\end{abstract}

Keywords - Engineering students, active learning, participation, performance, teaching strategy.

\section{INTRODUCTION}

The increasing development of technology and access to online information or educational material by a wide range of students has contributed to nurture the ideas groomed by education professionals consisting to depart from the traditional educational philosophy which is instructor-centered to embrace the more flexible approach which is learnercentered [1]. In the former approach the teacher or lecturer is likely to play the main role as he/she is expected to pass knowledge and information onto their students who passively receive what is directed toward them; while in the later approach the students are motivated to interact more often and contribute significantly to classroom or subject related activities acquiring knowledge in the process. There is however a conflicting opinion among professional with regard to the approach suitable to achieve effective teaching and learning. Which therefore reflects the tendency on the field where general practice makes use of either direct instruction, inquired-based learning, cooperative learning or different combinations. Recent findings by educators suggest that

Manuscript received August 20, 2017. This work was supported in part by the North-West University.

E. Fosso-Kankeu is with the School of Chemical and Minerals Engineering at the North-West University, Potchefstroom, South Africa. teaching strategies that more actively engage learners with content and each other may stimulate critical thinking, improve student motivation to learn and fosters skills needed for life-long learning [2, 3, 4]. In other words, learning through the traditional approach of memorization is likely to result in students forgetting very quickly as without clear understanding it is difficult to apply the information to future reasoning [5]. In implementing innovative teaching strategies, it is important to bear in mind that the type of active learning activities that can be best received by students as well as increase their understanding and performance is subject/module dependent [6]. Therefore, in this study it was important to evaluate the response of students and the impact of an innovative teaching method (with emphasis on research investigation and students presentations) on their performance over two years. A questionnaire was administered to obtain the opinions of students with regard to different aspects of the teaching strategy and the rates of students passing the module before and after implementation of the new method were compared.

\section{METHODOLOGY}

\section{A. Teaching Strategy}

\section{Former Teaching Strategy}

The teaching approach used before 2016 was mostly based on "teacher-led demonstration" also known as direct instruction or traditional teaching strategy, considering the following aspects:

a- Presentation of the notes by the lecturer assisted by powerpoint

b- Availability of notes on efundi after contact session

c- Tutorial

d- Project.

\section{New Teaching Strategy}

A number of activities were added to the contact session content to promote active learning, moving from a lecturerbased teaching format toward a learner-centered teaching format to promote more interactions between the lecturer and the learners as well as between learners. The new content of the course was as follows: 
TABLE I:

COURSE DELIVERY METHODS AND EXPECTED OUTCOMES

\begin{tabular}{|c|c|c|}
\hline & Course delivery methods & Expected outcome \\
\hline $\mathrm{a}$ & $\begin{array}{l}\text { Availability of notes of } \\
\text { efundi }\end{array}$ & $\begin{array}{l}\text { this approach is conceived to allow } \\
\text { students to be prepared before class }\end{array}$ \\
\hline b & $\begin{array}{l}\text { Explanation of the key } \\
\text { scientific principles of a } \\
\text { given chapter by the } \\
\text { lecturer at the beginning } \\
\text { of the class }\end{array}$ & $\begin{array}{l}\text { this was conceived to ensure that complex } \\
\text { and key concepts are explained to } \\
\text { facilitate the understanding of the chapter } \\
\text { or unit }\end{array}$ \\
\hline c & $\begin{array}{l}\text { Presentation without } \\
\text { power point and } \\
\text { interaction with students } \\
\text { through questions- } \\
\text { answers practice }\end{array}$ & $\begin{array}{l}\text { this was adopted to encourage students } \\
\text { participation and involvement during class }\end{array}$ \\
\hline d & $\begin{array}{l}\text { Student presentation of } \\
\text { notes }\end{array}$ & $\begin{array}{l}\text { this approach was conceived to : - } \\
\text { encourage students to read their notes and } \\
\text { get prepared before class, and develop } \\
\text { presentation skills; - Reward on the daily } \\
\text { basis student effort and minimize the } \\
\text { impact on nonacademic challenges on } \\
\text { their performance }\end{array}$ \\
\hline $\mathrm{e}$ & Research topic & $\begin{array}{l}\text { this approach was conceived to keep } \\
\text { student updated with new development in } \\
\text { the field of study and improvement of } \\
\text { presentation skill }\end{array}$ \\
\hline f & The use of videos & $\begin{array}{l}\text { this is used for illustration of the concepts } \\
\text { discussed and intended to improve the } \\
\text { understanding }\end{array}$ \\
\hline $\mathrm{g}$ & Tutorial & $\begin{array}{l}\text { this practice is adopted to improve the } \\
\text { understanding of the notes, allow students } \\
\text { to test their knowledge and familiarize } \\
\text { themselves with the type of questions } \\
\text { related to subject covered }\end{array}$ \\
\hline $\mathrm{h}$ & Project & $\begin{array}{l}\text { this allows students to think out of the box } \\
\text { by considering the implementation of } \\
\text { knowledge acquired in the module, and } \\
\text { also allows to develop the writing skill of } \\
\text { students }\end{array}$ \\
\hline $\mathrm{i}$ & $\begin{array}{l}\text { Overall approval (>75\% } \\
\text { agreement) }\end{array}$ & $\begin{array}{l}\text { Suitability of the teaching strategy to } \\
\text { achieve better learning outcomes } \\
\text { (understanding of the module and } \\
\text { improvement of students performances) }\end{array}$ \\
\hline
\end{tabular}

\section{B. Assessment of the Teaching Strategy}

The assessment of the suitability of the newly adopted teaching approach was based on students' participation, performance as well as students perceptions of the teaching approach.

1- The rate of students passing the module after the first opportunity was compared before and after implementation of the new teaching approach.

2- Students perceptions toward the new teaching approach were obtained through administration of questionnaires in which the scoring of a teaching strategy (a-h) meeting its objectives was based on a scale of agreement or disagreement. 3- Although the students participation was not purposely measured, based on the experience and observation of the lecturer, estimation could be made.

\section{RESULTS AND DISCUSSION}

\section{A. Student Participation}

As mentioned previously, this aspect was not purposely measured; however, the lecturer noticed a considerable increase of the participation of students as there were more interactions with the lecturer as well as among themselves. This was likely due to the fact the new design of the course delivery compelled the students to be actors and not just spectators, as they had to be present to understand the key principles of the chapter covered (delivery of part "b" not available in power point) and participate in debates during presentations (delivery of parts "d" and "e") and enjoy the fun part of research investigation.

\section{B. Students' Perceptions}

The assessment of students' perceptions with regard to the new teaching strategy is shown in Figure 1; it can be observed that in general all course delivery methods are approved by more than $50 \%$ of the class, however, in this context it is important to strive for a total approval of the medium of course dispensation. The lowest score recorded for the teaching strategy (c) results from the fact that would like to have the power point after the lecturer presentation; however, the intention here was to increase the interaction between the lecturer and students, which may decrease when students concentrate mostly on the slides or are guaranty to have the slides after class. Overall, the new strategy scored $80 \%$ significant approval by the students, which is encouraging.

\section{Assessment of teaching strategy}

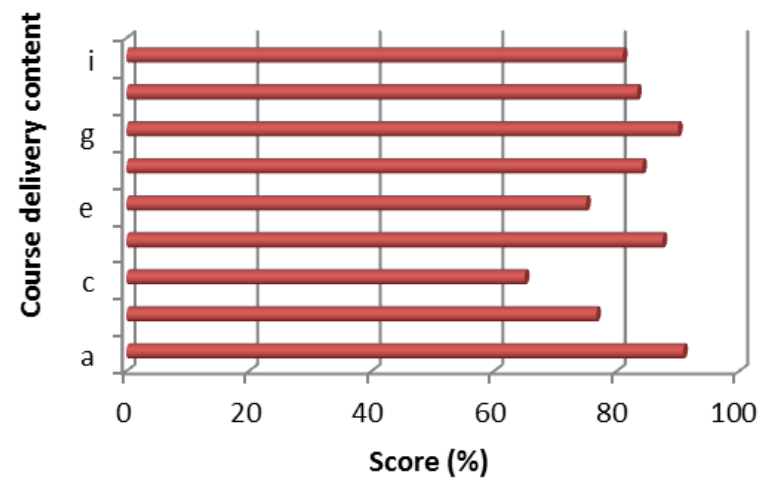

Fig 1. Scoring of course delivery content based on students' perceptions

\section{Students Performances}

The performance of students as indicated by their marks at the first opportunity exams was compared before and after implementation of the new teaching strategy; the recorded data are shown in Table 1:

TABLE 2: STUDENTS PERFORMANCES BEFORE AND AFTER IMPLEMENTATION OF NEW TEACHING STRATEGY

\begin{tabular}{|l|c|c|}
\hline \multirow{2}{*}{\begin{tabular}{c} 
Period \\
\cline { 2 - 3 }
\end{tabular}} & $\begin{array}{c}|c| \\
\text { Class average mark } \\
\%\end{array}$ & $\begin{array}{c}\text { Module throughput rate } \\
\%\end{array}$ \\
\hline Before & 52 & 83 \\
\hline After & 62 & 88 \\
\hline
\end{tabular}

According to the results in Table 2, the students' 
performances improved after implementation of the new teaching strategy in term of the average mark as well as the percentage of students who passed the module after the first opportunity exam.

\section{CONCLUSION}

The diversification of activities for the delivery of course implemented for stimulation of active learning has contributed to achieved to expected learning outcomes such as students participation and performance improvement, among engineering students at the North-West University. However, an important aspect of active learning which is understanding of the module for lasting knowledge cannot only be assessed based on the module pass rate, but also long after the students have completed their degree such application of the knowledge in the professional life. Further investigations are also required to ensure consistency and influence of emerging academic challenges.

\section{ACKNOWLEDGMENT}

The author is grateful to the honest participation of the fourth-year students in the survey.

\section{REFERENCES}

[1] B.B. Barr and J. Tagg. "From teaching to learning - a new paradigm for undergraduate education". Change. Vol. 27, no. 6, pp 12 - 15, 1995.

[2] E. Fosso-Kankeu. "Enhancing engineering students participation and performance through continuous evaluation and research approach". 7th Teaching and Learning Conference 2017. Centre for Teaching and Learning. 6 \& 7 June 2017, Vanderbijlpark - South Africa, 2017.

[3] D. Kember and L. Gow. "Orientations to teaching and their effect on the quality of student learning". J. Higher Educ. Vol. 65, no 1, pp 58-74, 1994.

[4] B.L. Gleason, M.J. Peeters, B.H. Resman-Targoff et al. "An activelearning strategies primer for achieving ability-based educational outcomes". American Journal of Pharmaceutical Education. Vol. 75, no. 9, pp 1-12, 2011.

[5] C.W. Ueckert, J. Gess-Newsome. "Three activities to increase student involvement in learning". The Science Teacher. Vol. 75, no. 9, pp 47-52, 2008.

[6] W.J. McKeachie, M. Svinicki. "McKeachie's Teaching Tips". 12th ed. Boston, MA: Houghton Mifflin, 2006.

The corresponding author is currently an Associate Professor in the School of Chemical and Minerals Engineering at the North-West University (Potchefstroom). He is an NRF rated researcher who has published journal articles, book chapters and book.

Prof Elvis Fosso-Kankeu has been the recipient of several merit awards. 